\title{
CYTOLOGICAL ABNORMALITIES IN PENNISETUM DUBIUM
}

\author{
P. GILDENHUYS and K. BRIX \\ University of Natal, Pietermaritzburg, South Africa
}

Received 10.i.58

\section{INTRODUCTION AND MATERIALS}

THE genus Pennisetum consists, cytologically, of two groups of species, one with a basic chromosome number of $x=7$ and the other with $x=9$ (Darlington and Wylie, 1956). The annual large-seeded $P$. typhoides $(2 n=14)$ has been used in hybridisation programmes in an endeavour to breed a large-seeded perennial for use in ley farming (Gildenhuys, 1950). It was crossed with perennial $P$. purpureum $(2 n=28)$, the only other known species in the $x=7$ group.

In a search for other perennial species to be used for crossing, the senior author collected a type in the Ermelo district of the Eastern Transvaal. He found the following chromosome numbers in plants of this collection ; $2 n=56,63,66,67,70$ and 86 (Gildenhuys, I 95 I).* These plants were remarkably uniform both in their natural habitat and in progenies raised from seed. On crossing one plant of his collection onto $P$. typhoides he obtained one hybrid plant which had only 2 I chromosomes. It had received 14 chromosomes from a parent with at least 56 . The behaviour of the polyploid parent became a matter of interest and it is this behaviour, reported below, which has led us to suggest for this type the nomen P. dubium. $\dagger$

\section{OBSERVATIONS}

\section{(i) Mitosis}

Nine clones grown in pots in the field and numerous natural seedlings germinated in an incubator at $25^{\circ} \mathrm{C}$. all showed varying numbers of chromosomes in the same root tip. Complements varying in number from 14 to 84 ( 161 cells) were observed, the most frequent number being 66 (fig. IA). Cell size increased with chromosome number.

To obviate the possibility of over-squashing (Walker et al., 1954), counts from intact cells only were recorded.

* This type was identified by Professor A. P. Goossens as P. sphacelatum. Since then, however, Dr Hubbard and others have classified it as P. macrourum. Crook (1955) pointed out the difficulties of distinguishing between these two species, but according to $\mathrm{Mr} \mathrm{D}$. Killick specimens at Kew, where this grass was sent for matching, are distinct. The chromosome number of $P$. sphacelatum has not yet been determined. The number given by Darlington and Wylie for $P$. macrourum is $2 n=45$, as determined by Avdulov. Mr D. Killick, who checked on Avdulov's original publication, states that this number should read $2 n=54$ and also points out that there cannot be certainty that Avdulov's material was correctly named.

$\dagger$ Root tips were stained and squashed in aceto-carmine with ferric chloride, anthers in acetic-orcein. Both were fixed in Carnoy's $(6: 3: 1)$. Root tips were sometimes prefixed for $2 \frac{1}{2}$ hours in a saturated aqueous solution of $\alpha$-bromonaphthalene. 
Cells with several nuclei were also observed. The timing of nuclear divisions in these cells was often irregular. In the same cell

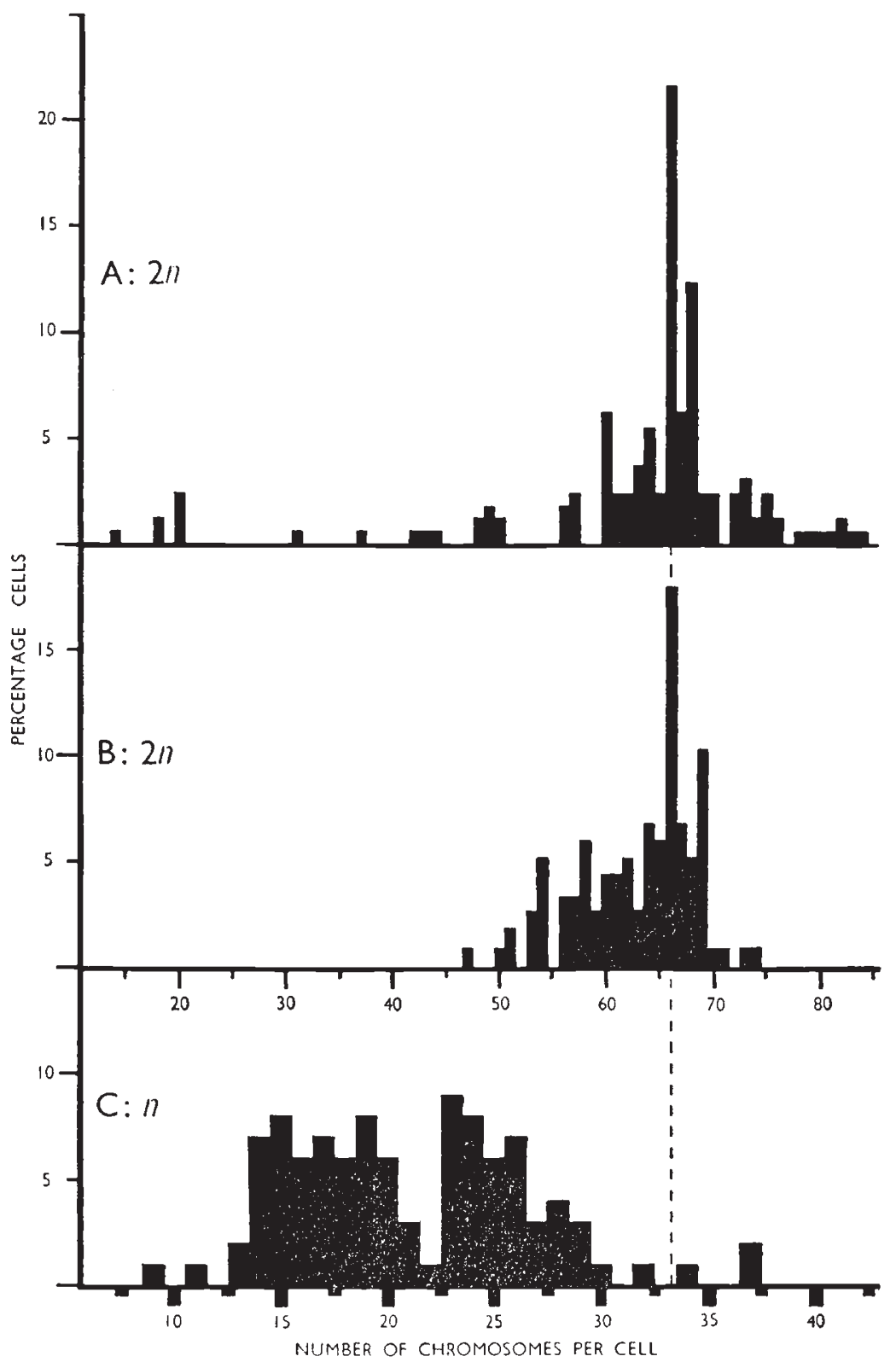

FIG. 1.-Frequency distributions of different chromosome complements per cell in root tips and anthers of $P$. dubium.
A. Root tip squashes $(2 n)$.
B. P.M.C. squashes-Meiosis I $(2 n)$.
C. P.M.C. squashes-Meiosis II $(n)$.

one or more nuclei might be in the resting stage, whilst the remainder were in any one of the different phases of division (fig. 2A-B). The 
different nuclei in a cell contained chromosomes ranging in number from a few (I4) to as many as 66.

Again, there might be in the same cell groups of chromosomes at all phases of mitosis. Such groups could be distinguished from those formed by the simultaneous division of more than one nucleus in the same cell. This happened both in pretreated and in untreated material. The number of groups was mostly 2 to 4 (fig. 2D), but in rare cases 5 or 6 . In some cells single chromosomes or very small groups of chromosomes appeared to be scattered at random in the
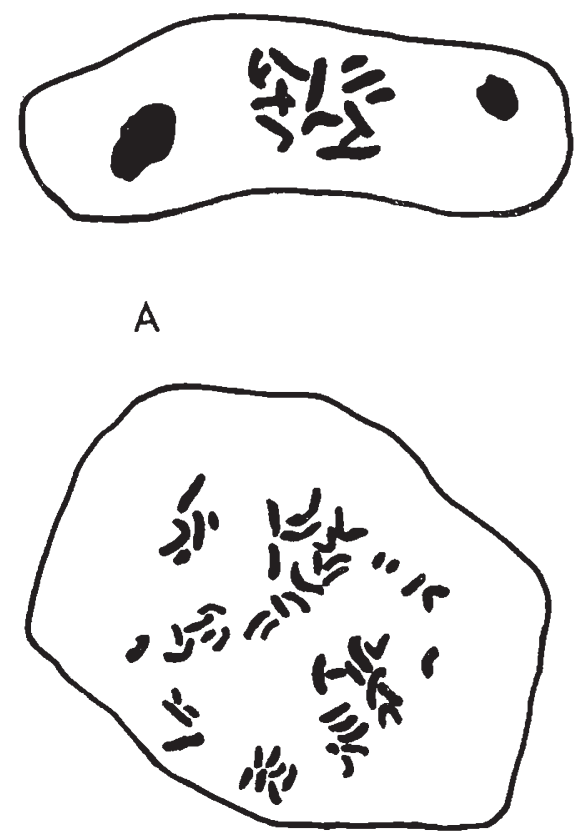

C
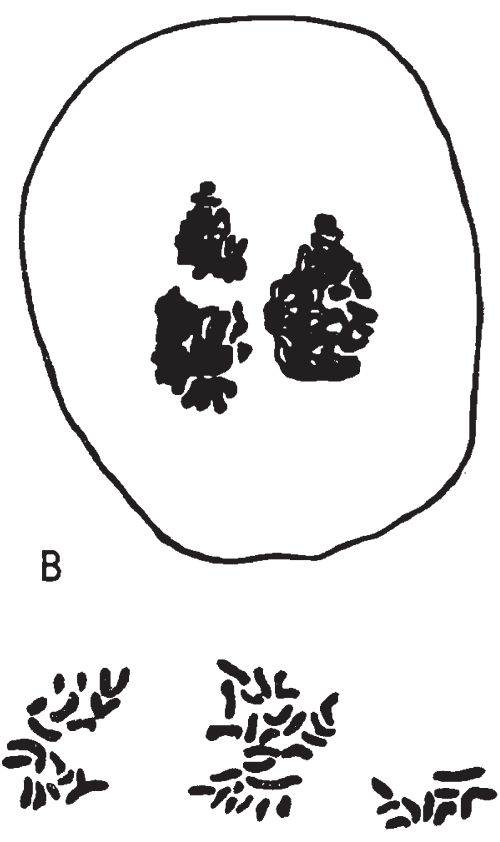

D

FIG. 2.- Mitotic abnormalities in Pennisetum dubium. A-B. Timing of division in R.T. cells with more than one nucleus. A. Two resting nuclei and one metaphase nucleus with 14 chromosomes. B. Three late prophase nuclei of unequal size. C-D. Group formation of chromosomes. C. Many small groups and scattered individuals at metaphase. D. Three groups at metaphase. All figs. $\times 1260$.

cytoplasm, away from the main groups (fig. 2C). In cells with a large number of groups it was occasionally possible to count the number of chromosomes and they varied from 2 to 22 per group in equal or unequal numbers.

Equatorial views of metaphase occasionally showed groups not orientated on the equator. Tripolar, quadripolar and split spindles could be seen at anaphase, and lagging chromosomes were also observed. Cells with telophase nuclei often also had micronuclei and/or individual chromosomes scattered in their cytoplasm. Cell walls were rarely formed. 
Very few cell divisions were found in the root tips of two clones and in these multinucleate cells appeared to be more prevalent than in the remaining clones. Table I shows the frequency of all types of abnormalities at all phases of mitosis in 5 different clones.

TABLE I

Frequencies of abnormal mitotic cell divisions in P. dubium :

Numbers of cells examined in each phase are shown in brackets

\begin{tabular}{|c|c|c|c|c|c|}
\hline \multirow{2}{*}{ Plant no. } & \multicolumn{3}{|c|}{ Percentage of abnormal cells } & \multirow{2}{*}{$\begin{array}{l}\text { Total cells } \\
\text { examined }\end{array}$} & \multirow{2}{*}{ Means } \\
\hline & Prophase & Metaphase & $\begin{array}{c}\text { Anaphase and } \\
\text { Telophase }\end{array}$ & & \\
\hline $\begin{array}{r}5 \\
3 \\
4 \\
\text { I I } \\
6\end{array}$ & 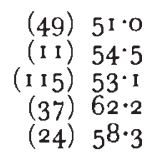 & $\begin{aligned}(91) & 25 \cdot 3 \\
(24) & 20 \cdot 8 \\
(184) & 23 \cdot 9 \\
(59) & 28 \cdot 8 \\
(60) & 40 \cdot 0\end{aligned}$ & $\begin{aligned} \text { (69) } & 20 \cdot 3 \\
(20) & 40 \cdot 0 \\
\text { (I I 5) } & 45 \cdot 2 \\
(49) & 44 \cdot 9 \\
(65) & 49 \cdot 2\end{aligned}$ & $\begin{array}{r}209 \\
55 \\
414 \\
145 \\
149\end{array}$ & $\begin{array}{l}29 \cdot 7 \\
34 \cdot 5 \\
37 \cdot 9 \\
42 \cdot 8 \\
47 \cdot 0\end{array}$ \\
\hline Means & $(236) 54 \cdot 7$ & $(418) 27 \cdot 1$ & $(318) 40 \cdot 3$ & $97^{2}$ & $3^{8 \cdot 1}$ \\
\hline
\end{tabular}

(ii) P.M.C. meiosis

Abnormalities similar to those in the root tips were also encountered at meiosis, but they were less intense and less frequent (table 2).

TABLE 2

Frequencies of abnormal meiotic cell divisions in $\mathrm{P}$. dubium :

Numbers of cells examined in each phase are shown in brackets

\begin{tabular}{|c|c|c|c|c|c|c|c|c|}
\hline \multirow{3}{*}{$\begin{array}{c}\text { Plant } \\
\text { no. }\end{array}$} & \multicolumn{6}{|c|}{ Percentage of abnormal cells } & \multirow{3}{*}{$\begin{array}{c}\text { Total } \\
\text { cells } \\
\text { exam- } \\
\text { ined }\end{array}$} & \multirow{3}{*}{ Means } \\
\hline & \multicolumn{2}{|c|}{ Metaphase } & \multicolumn{2}{|c|}{ Anaphase } & \multicolumn{2}{|c|}{ Telophase } & & \\
\hline & I & II & I & II & I & II & & \\
\hline $\begin{array}{r}3 \\
5 \\
11 \\
6\end{array}$ & $\begin{array}{rr}(200) & 3 \cdot 5 \\
(2 \mathrm{I} 7) & 6 \cdot 9 \\
(202) & 2 \cdot 5 \\
(500) & \mathrm{I} 1 \cdot 2\end{array}$ & 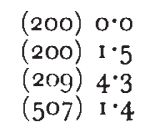 & $\begin{array}{r}(67) 0 \cdot 0 \\
(69) 4 \cdot 4 \\
(33) 6 \cdot 0 \\
(104) 3 \cdot 8\end{array}$ & $\begin{array}{rr}(9 \mathrm{I}) & \mathrm{I} \cdot \mathrm{I} \\
(86) & 3.5 \\
(68) & 4 \cdot 4 \\
(\mathrm{I} 27) & 5.5\end{array}$ & $\begin{array}{ll}(200) & 0.0 \\
(200) & 0.0 \\
(200) & 1 \cdot 0 \\
(161) & 0.6\end{array}$ & $\begin{array}{ll}(200) & 0 \cdot 0 \\
(200) & 0 \cdot 0 \\
(178) & 1 \cdot 6 \\
(301) & 0 \cdot 3\end{array}$ & $\begin{array}{r}95^{8} \\
972 \\
890 \\
I 700\end{array}$ & $\begin{array}{l}0.84 \\
2.47 \\
2 \cdot 70 \\
4.47\end{array}$ \\
\hline Means & $\left(\begin{array}{l}1119) \quad 7 \cdot 4^{2} \\
(15)\end{array}\right.$ & $(\operatorname{lin} 6)$ i 70 & (273) 3.30 & $(372) 3.76$ & $(76 \mathrm{I}) 0.39$ & $(879) 0.46$ & 4520 & $2 \cdot 9^{2}$ \\
\hline
\end{tabular}

Two or even threc ‥rlei occurred in certain P.M.G's. These cells obviously arose from abnormal pre-meiotic mitoses which resulted in two types:-(i) binucleate cells which arose through failure of cell-division and (ii) those in which one of the nuclei of binucleate cells had undergone a reduction division, thus producing two reduced interphase nuclei and one persistent pre-meiotic resting nucleus. 
These two types could be distinguished by the sizes and positions of their nuclei. The timing of the nuclear divisions in such cells was almost invariably irregular (fig. 3D), and none of them produced countable chromosome plates. The few nearly countable ones revealed upwards of 50 in the same cell with one or two resting nuclei. Interphase dyads had no more than two nuclei per cell. Some of these were simultaneously dividing with two metaphase plates, one above the other in the same cell. Rarely one cell of a dyad contained a normal nucleus whilst the other contained only a micronucleus surrounded by stained material.

Tripolar and quadripolar spindles also occurred at anaphase of both divisions. Such spindles would account for the presence of two nuclei in cells of interphase dyads. From the sizes of these nuclei they could not be confused with micronuclei following lagging.

Groups of chromosomes were also observed at all phases of both divisions. Here, however, two complications arose. First, the occurrence of sticky chromosomes precluded the possibility of distinguishing clearly, in first divisions, between the types of groups found at mitosis and the type formed as a result of stickiness or a combination of both (fig. 3c). Second, lack of association and also of co-orientation of both bivalents and univalents together with stickiness could equally well account for the presence, in certain cells, of individual chromosomes and small groups scattered away from the main groups. Stickiness was more pronounced in second divisions, but here, groups similar to those at mitosis could, in certain cases, be distinguished, uncomplicated by chiasma associations.

Stickiness frequently led to clumping (fig. 3c). In first division preparations, clumps often occurred in the same cell as distinguishable univalents, bivalents, etc. Stickiness persisted through interphase in which many preparations had the two nuclei joined by chromatin material in the form of either a broad band (fig. $3 \mathrm{~A}$ ) or thin extended threads curling in different directions through the cytoplasm (fig. $3 \mathrm{~B}$ ). Chromatin material joining sticky interphase nuclei was distinct from inversion bridges.

Chromosome numbers. As a result of stickiness and also of variation in chromosome numbers, it was often difficult to determine the associations and hence the chromosome numbers in first divisions. Consequently, the chromosome numbers in first P.M.C. divisions were determined entirely from normal or nearly normal early anaphases. These numbers varied from 47 to 74 in II 7 cells, the most frequent number again being 66 (fig. IB). In dyad cells, in which stickiness was less severe, the numbers varied from 9 to 37 (Ior cells), the most frequent number being 23 (fig. IC).

Chromosome associations and distribution. From P.M.C.'s undergoing normal or near normal first divisions the chromosome associations in diakinesis and MI reflected in table 3 were obtained. 
The lowest degree of association was in a cell with $27 \mathrm{I}+\mathrm{Ig} \mathrm{II}=65$. Four cells $(7 \cdot 8$ per cent.) showed no univalents. In these the associations were :-

$$
\begin{aligned}
& 2 \mathrm{III}+30 \mathrm{II}=66 \\
& \text { I III }+3 \mathrm{III}=65 \\
& 33 \mathrm{II}=66 \text { and }
\end{aligned}
$$

I VI + I IV +26 II $=62$ (the only cell containing a sexivalent).
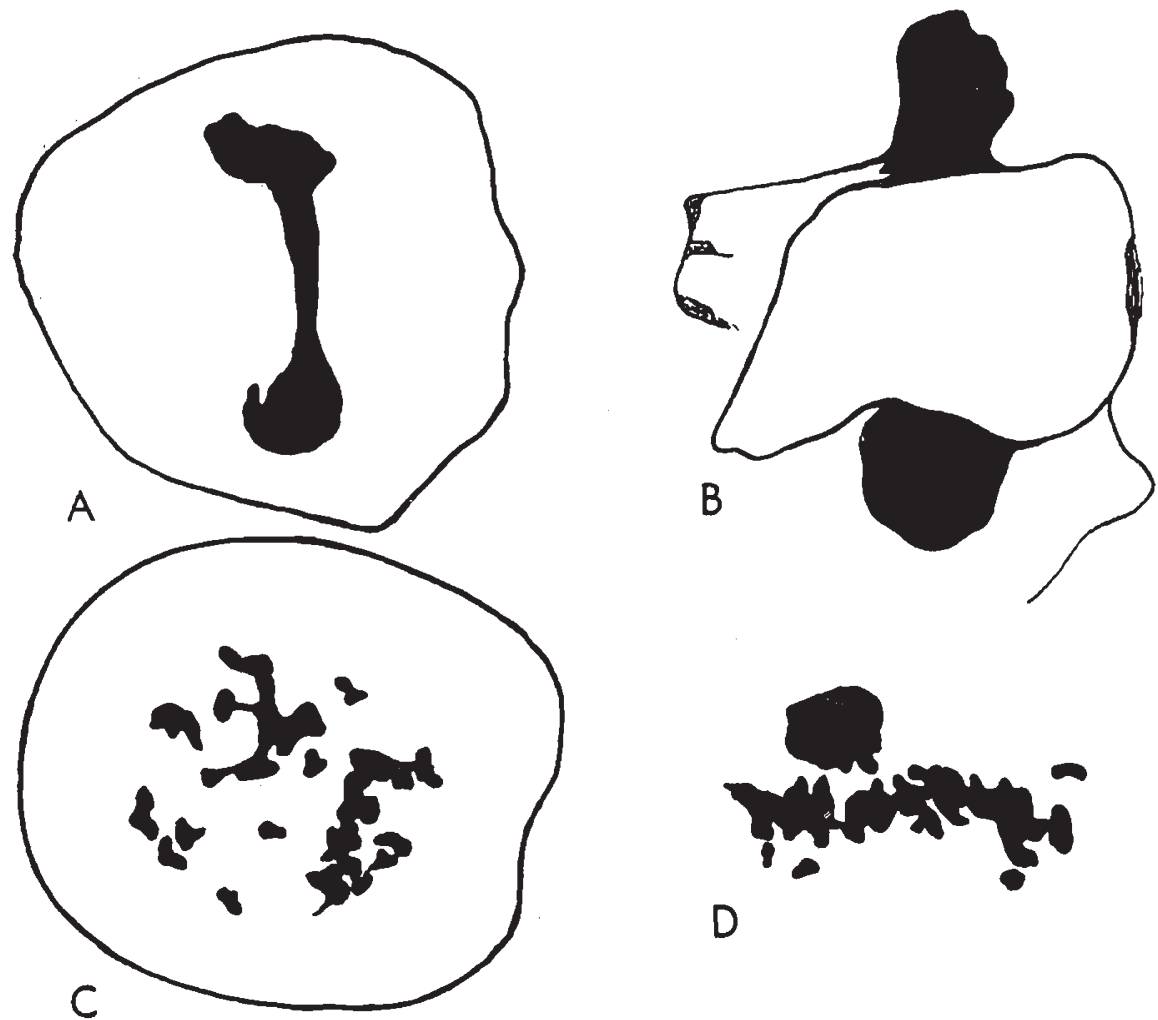

Fig. 3.--Meiotic abnormalities in Pennisetum dubium. A-C. Stickiness at meiosis I in P.M.C.'s. A-B. Sticky interphase nuclei joined by chromatin material in broad bands (A) or in thin curling extended threads (B). C. Chromosomes joined and aggregated into groups at MI. D. Timing of division in P.M.C. with more than one nucleus-one resting and one MI nucleus. All figs. $\times 1260$.

Eighteen cells $(35 \cdot 3$ per cent.) contained less than 5 univalents.

Univalents divided either at first or at second division. Bridges occurred in 70.5 per cent. of first divisions (table 4 ). They rarely appeared at second division.

In certain MI plates there was a lack of co-orientation of bivalents, which lay scattered in the cytoplasm whilst others were co-orientated. Occasionally however some were found to divide quite normally after the others had nearly reached the poles. Those which failed to orientate by late AI then migrated to the poles as undivided bivalents. 
At late TI they were sometimes still undivided and lying outside the nuclei. They were not seen to persist as bivalents into second

TABLE 3

Chromosome associations in P.M.C.'s at diakinesis and MI in P. dubium

\begin{tabular}{|ll|c|c|c|c|c|c|c|}
\hline \multicolumn{1}{|c|}{ Associations } & VI & IV & III & II & I & $2 n$ & $\begin{array}{c}\text { Total cells } \\
\text { examined }\end{array}$ \\
\hline Totals & $\cdot$ & I & 21 & 12 & 1441 & 309 & 3317 & \\
\hline Means & $\cdot$ & 0.02 & 0.41 & 0.24 & $28 \cdot 25$ & 6.06 & 65.04 & 51 \\
\hline Range & $0-1$ & $0-2$ & $0-3$ & $17-33$ & $0-27$ & $50-73$ & \\
\hline
\end{tabular}

division. In AII, however, there were occasionally undivided univalents, and they may have been the products of bivalents which had divided in the second division.

\section{TABLE 4}

Frequencies of bridges at first meiotic divisions of $\mathrm{P}$. dubium

\begin{tabular}{|c|c|c|c|c|c|c|c|}
\hline Number of bridges & o & 1 & 2 & 3 & 4 & 5 & Mean $=1 \cdot 44$ \\
\hline Number of cells & $3^{1}$ & 26 & 28 & 12 & 7 & I & Total $=105$ \\
\hline
\end{tabular}

Chromosome distribution at anaphase varied greatly. In cells with no laggards this variation was of the order of a $21: 35$ distribution to an even distribution as high as $33: 33$ for AI and $24: 39$ to even

TABLE 5

Frequencies of laggards or micronuclei in meiosis of $\mathrm{P}$. dubium

\begin{tabular}{|c|c|c|c|c|c|c|c|c|c|c|c|c|c|c|c|c|c|c|c|c|c|}
\hline \multirow{2}{*}{ Phase } & \multicolumn{19}{|c|}{ Number of laggards or micronuclei per cell } & \multirow{2}{*}{$\begin{array}{c}\text { No. of } \\
\text { cells }\end{array}$} & \multirow{2}{*}{ Means } \\
\hline & o & I & 2 & 3 & 4 & 5 & 6 & 7 & 8 & 9 & 10 & 11 & 12 & 13 & 14 & 15 & 1 & I & I & & \\
\hline Inter & 57 & 10I & 112 & 88 & 60 & 33 & 33 & 7 & 9 & 11 & 4 & 5 & 7 & $\mathbf{I}$ & 5 & I & 1 & 0 & 3 & $53^{8}$ & $3 \cdot 27$ \\
\hline TII & 103 & 132 & 102 & 69 & 55 & 18 & 30 & 10 & 9 & 3 & 4 & & & & & & & & & 535 & $2 \cdot 3^{2}$ \\
\hline
\end{tabular}

$(24: 24$ to $33: 33)$ for AII. At interphase 89.4 per cent. and at TII 80.7 per cent. of cells showed laggards or micronuclei and these varied in number from $o$ to 18 in the former and o to 10 in the latter phase (table 5).

Cell walls were usually found at late TI or later. Immediately cytokinesis had set in cells separated easily with very slight pressure. 
Tetrads and pollen. Tetrads almost invariably had one or more micronuclei scattered in their cytoplasm. Other than size differences, the only abnormality which occurred at this stage was the presence of an occasional triad or a triad with a shrunken fourth cell containing a micronucleus surrounded by darkish material.

Pollen collected immediately after dehiscence revealed no significant differences between plants in either the percentage of stainable pollen or the sizes of the pollen grains. Of 4603 grains $28 \cdot 0$ per cent. did not stain as compared with 13.3 per cent. (I 290 counted) in the diploid $P$. typhoides. The grains varied in size from 19 to 33 divisions on the ocular micrometer disc (mean $=25^{\circ}$ ) as against 20 to 25 (mean $=22 \cdot 6)$ for $P$. typhoides (table 6).

\section{TABLE 6}

Frequencies of pollen grains of different sizes in

P. typhoides and P. dubium

\begin{tabular}{|c|c|c|c|c|c|c|c|c|c|c|c|c|c|c|c|c|c|}
\hline \multirow{2}{*}{ Species } & & \multicolumn{15}{|c|}{ Sizes in divisions of ocular micrometer } & \multirow{2}{*}{ Means } \\
\hline & & 19 & 20 & 21 & 22 & 23 & 24 & 25 & 26 & 27 & 28 & 29 & 30 & $3^{I}$ & $3^{2}$ & 33 & \\
\hline P. typhoides & . & & I & 7 & 23 & II & 6 . & 5 & & & & & & & & & $22 \cdot 55$ \\
\hline P. dubium & . & 2 & 13 & I5 & 26 & 45 & 59 & 225 & 85 & 82 & $5^{8}$ & 45 & 50 & 9 & 3 & 2 & $25 \cdot 94$ \\
\hline
\end{tabular}

\section{ABNORMALITY AT MITOSIS}

The mitotic abnormalities appear to be of three main kinds :

(I) Delayed cytokinesis in otherwise normal cell divisions. If the chromosome number of this grass is taken as $2 n=66$ then the highest number observed $(2 n=84)$ indicates that cell-wall formation seldom fails altogether. The presence of a large nucleus in the same cell as about 66 metaphase chromosomes was the nearest approach to a cell with a doubled number that was observed. Multinucleate cells could, of course, have arisen through failure of cytokinesis, but they may also be the result of the other abnormalities discussed below. It seems more likely that cytokinesis seldom fails altogether but that it is delayed until subsequent division of the chromosomes. Because of the high frequency of abnormal anaphases, telophases and prophases as compared with metaphases (table I), it is thought that it generally sets in after the first subsequent mitotic prophase. Table I includes as "abnormal" also normal divisions of more than one nucleus per cell.

(2) Spindle abnormalities. Although the presence of a spindle was not demonstrated, the discontinuous arrangement of chromosomes on equatorial plates (fig. 2c) could be the result of a discontinuous or incompact spindle as described by Darlington and Thomas (I937) 
in meiosis of a Festuca-Lolium derivative. Tripolar and split or quadripolar spindles are evidently present in some cells. In cases where three nuclei appeared in the same somatic cell, one was often very much larger than the other two (fig. 2B), indicating the possibility that a tripolar spindle and failure of cell-wall formation after telophase may have been the cause. Owing to the fact that cytokinesis was so rare, an actual reduction in chromosome number due to spindle abnormalities was never observed. That this type of abnormality may lead to variation in chromosome number is, however, evident.

(3) Group formation of chromosomes. Over-squashing (Walker et al. l.c.) could well be the reason for the presence of groups, especially when these groups are separated by cytoplasmic "breaks". In this material, however, numerous apparently intact cells without such breaks were observed to contain groups of chromosomes. The possibility that the chromosomes could be irregularly distributed after cytokinesis in such cells is apparent.

These abnormalities are similar to those described by Snoad (I955) in Hymenocallis calathinum. Whether they are all due to a single basic cause which upsets the spindle (Vaarama, I949 and Snoad, 1.c.) or whether they arise from separate causes (Östergren, I950) cannot be stated without inducing them experimentally, as has been done by Huskins et al. (I950) and his school when they propounded their ideas on "somatic meiosis", " reductional grouping" and "segregational reduction". Nevertheless, noteworthy facts are that they exhibit a wide range and that they occur naturally with a high frequency.

The views of Wilson et al. (I952) regarding the "semi-separable zones of activity" of the spindle might well explain different manifestations of an abnormality which could be induced extraneously, but which could, as appears in this case, also arise from the genotype. In fact, as Sachs (I 954) has pointed out, not only can subdiploid variation be caused by environmentally controlled mitotic abnormalities, but certain gene combinations can cause distinct abnormalities such as split spindles in both mitosis and meiosis, multipolar spindles at meiosis and so on. In this case environmental agencies could be excluded, as the same abnormalities occurred in root tips of seedlings germinated under normal conditions.

\section{ABNORMALITY AT MEIOSIS}

Abnormalities similar to the three types described above also arise at meiosis. Added to these there are the stickiness and the abnormal reduction after the first meiotic divisions. Stickiness has been observed in many organisms by different workers. Evidence of the causes of this abnormality is scarce and vague. Beadle (1932) attributed stickiness in Zea mays to a single recessive gene. Walters (I950) stated, without further reference, that " ... interspecific grass hybrids frequently have sticky meiotic chromosomes and this condition may 
also be influenced by environmental conditions". Ono (195I) explained similar phenomena in intergeneric hybrids in Cichorieæ by his " hypothesis of residual affinity", whereby it is assumed that in nuclei of heterogeneous origin the presence of homologous sections, large or small, in different chromosomes, will cause secondary association to the extent of forming netlike configurations at early diakinesis. Recently Davies (1956) pointed out that stickiness often occurs in both meiotic divisions in species of plants and insects which lack localised centromeres. In almost all reported cases stickiness is accompanied by breakage or loss of chromosomes. The occurrence of stickiness at both meiotic divisions and its effects suggests that it is connected with the other abnormalities.

The highly reduced numbers of chromosomes in dyads might be the result of several causes. Although somatic cells with chromosome numbers as low as 14,18 and 20 continue to divide mitotically they are eliminated, probably through competition, by the time microsporogenesis takes place and only the higher numbers occur at this stage (fig. IB). After first meiotic division, however, an abnormal reduction in number takes place (fig. IC). This reduction could be the result of spindle abnormalities arising in first division or of lack of association and of co-orientation with resultant lagging. The frequency of the former (table 2) and of laggards and micronuclei (table 5) and the sizes of these micronuclei do not explain this loss however. Stickiness in itself probably contributes in part to this loss, perhaps as a result of fragmentation and disintegration. Thus, for instance, uneven distributions at AI were not observed to be of the order which would result in daughter cells, one of which contained only a small micronucleus as described earlier. Because of the marked stickiness and also the lagging in second divisions, this reduction in chromosome number probably continues when tetrads are formed. Great variation in size of pollen grains (table 6) is therefore to be expected. Under these circumstances a lower percentage of stainable pollen might also be expected.

How then is polyploidy maintained? An explanation may be found in apomixis, which is probably more common in perennial grasses than is suspected. The hybrid shows, however, that pollen grains with chromosome numbers as low as 14 can be produced, and moreover, that such grains are viable and function in crosses.

\section{BASIC NUMBER}

As to the position of this species in a genus with basic chromosome numbers of 7 and 9, several possibilities exist. Either a new basic number for the genus should be added, or another explanation should be found for the occurrence of the number most frequently observed $(2 n=66)$. The types of abnormalities in this grass have been found more frequently in hybrids than in species and although 66 is neither 
a multiple of 7 nor of 9 the possibility of two such forms producing an allopolyploid is not to be overlooked. It is of course also likely that the peculiar chromosome numbers in this form may have arisen through the more common causes of aneuploidy, regardless of whether the original form was auto- or allopolyploid.

\section{SUMMARY}

I. Chromosome numbers of a Pennisetum species vary from $\mathrm{I}_{4}$ to 84 in root tips and 47 to 74 in P.M.C's. Most frequent number in both is 66 .

2. Spindle abnormalities and group formation of chromosomes are very frequent in mitosis, less frequent in meiosis. They could be the cause of variation in number.

3. After the first division in the P.M.C. there is an abnormal reduction in chromosome number. This might be attributed to loss which occurs often in both meiotic divisions. The most frequent complement is $n=23$.

4. A hybrid between this grass and $P$. typhoides $(2 n=14)$ with only 2 I chromosomes demonstrates the viability of pollen grains with I4 chromosomes.

5. Chromosome numbers in this species indicate (i) that a new basic number should be added to those already known for the genus $(x=7$ and $x=9$ ), or (ii) that it might be a hybrid between $x=7$ and $x=9$ forms.

6. The name $P$. dubium is suggested for this species.

Acknowledgment.-We are indebted to Professor C. D. Darlington for his suggestions on improving the text.

\section{REFERENCES}

BEADLE, G. W. 1932. A gene for sticky chromosomes in Zea mays. Z.I.A.V., 63, I 95-2 I 7 .

Crook, L. 1955. The Grasses and Pastures of South Africa. Central News Agency, Johannesburg.

DARLington, C. D., AND thomas, P. T. 1937. The breakdown of cell division in a Festuca-Lolium derivative. Ann. Bot., $1,747-762$.

darlington, C. D., ANd wylie, A. P. 1956. Chromosome Atlas of Flowering Plants. Allen and Unwin, London.

DAvies, E. W. 1956. Cytology evolution and origin of the aneuploid series in the genus Carex. Hereditas, 42, 349-365.

Gildenhuys, P. J. 1950. A new fodder grass, Farming in South Africa, 15, I89-191. giddenhuys, P. J. 1951. Pasture Research in South Africa. Progress Report No. 3, Grass Breeding. Dept. of Agric., Union of South Africa.

HUSKINS, G. L., AND GHENG, K. C. I950. Segregation and reduction in somatic tissues. IV. Reductional groupings induced in Allium cepa by low temperature. 7. Heredity, 4r, 13-18.

ono, H. 195I. Intergeneric hybridisation in Cichorieæ. X. Further studies in hybrids of Paraixeris denticulata and Lactuca Squarrosa. Co-ordinating Committee for Researches in Genetics, 2, 13-16. 
ÖSTERGREN, G. 1950. Cytological standards for the quantitative estimation of spindle disturbances. Hereditas, 36, 37 I-382.

sachs, L. 1954. The chromosome constancy of the normal mammalian uterus. Heredity, 8, I I 7-1 24 .

SNOAD, B. 1955. Somatic instability of chromosome number in Hymenocallis calathinum. Heredity, 9, 128-134.

VAARAMA, A. 1949. Spindle abnormalities and variation in chromosome number in Ribes nigrum. Hereditas, $35, \mathrm{1}_{3} 6-162$.

WALKeR, B. E., AND BoOTHROYD, E. R. 1954. Chromosome numbers in somatic tissues of mouse and man. Genetics, 39, 210-219.

WALTERS, M. S. I950. Spontaneous breakage and reunion of meiotic chromosomes in hybrid Bromus trinii $\times B$. maritimus. Genetics, $35,11-37$.

WILsON, G. B., TE MAY TSOU AND PETER HYYPio. 1952. Variations in mitosis. $\mathcal{f}$. Heredity, 43, 2 I I-2 I 5 . 